\title{
Pengaruh Filter Udara Berbahan Zeolit dan Fly ash Teraktivasi HCl-Fisik terhadap Prestasi Mesin Sepeda Motor 4 Langkah
}

\author{
Herry Wardono', Abdul Aziz², A Yudi Eka Risano ${ }^{3}$ \\ Jurusan Teknik Mesin, Fakultas Teknik Universitas Lampung \\ JIn. Prof.Sumantri Bojonegoro No.1 Gedung H FT Lt.2 Bandar Lampung, Indonesia \\ Email: herry.wardono@eng.unila.ac.id ${ }^{1}$, plettonic4494@gmail.com², yudi_95@yahoo.com³
}

\begin{abstract}
Abstrak
Menurut Direktur Jendral Minyak dan Gas Bumi (MIGAS) Kementrian Energi dan Sumber Daya Mineral (ESDM) cadangan minyak Indonesia hanya bisa bertahan hingga tahun 2028. Menanggapi permasalahan tersebut, salah satu cara adalah menghemat penggunaan bahan bakar minyak dengan memanfaatkan fly ash batubara dan zeolit alam sebagai penyaring udara (filter) kendaraan. Zeolit dan fly ash memiliki kemampuan menangkap uap air dan gas Nitrogen dalam udara, sehingga proses pembakaran menjadi lebih sempurna dan meningkatkan prestasi mesin menjadi lebih baik. Di dalam zeolit dan fly ash terdapat zat pengotor sehingga perlu dilakukannya aktivasi $\mathrm{HCl}$ untuk membersihkan zat pengotor tersebut. Kemudian zeolit dan fly ash dibuat berbentuk bulat dengan ketebalan $3 \mathrm{~mm}$ dan berdiameter $10 \mathrm{~mm}$ dan disusun menyerupai bentuk filter asli dari kendaraan motor uji. Temperatur aktivasi fisik (pengovenan) pelet zeolit dan fly ash yang digunakan $150^{\circ} \mathrm{C}, 175^{\circ} \mathrm{C}, 200^{\circ} \mathrm{C}$ dan $225^{\circ} \mathrm{C}$. Konsentrasi kimia yang digunakan normalitas $\mathrm{HCl} 0,25 \mathrm{~N} ; 0,5 \mathrm{~N} ; 0,75 \mathrm{~N} ; 1 \mathrm{~N} ; 1,5 \mathrm{~N}$; dan $2 \mathrm{~N}$. Dengan komposisi zeolit dan fly ash Z0:F100, Z25:F75, Z50:F50, Z75:F25 dan Z100:F0. Penelitian ini menggunakan 4 variasi pengujian yaitu pengujian jalan, pengujian stasioner, pengujian akselerasi dan pengujian emisi gas buang. Filter komposisi terbaik adalah filter Z75:F25 total persentasi sebesar 55,09\%. Filter aktivasi kimia $\mathrm{HCl}$ terbaik adalah filter $1 \mathrm{~N}$ total persentasi sebesar $75,74 \%$. Filter temperatur aktivasi fisik terbaik adalah filter $225^{\circ} \mathrm{C}$ total persentasi sebesar 58,31\%. Pada pengujian emisi gas buang kadar gas CO terbaik filter Z75:F25 1N $225^{\circ} \mathrm{C}$ sebesar $0,47 \%$ pada $2500 \mathrm{rpm}$. Penurunan kadar $\mathrm{HC}$ terbaik filter Z75:F25 $1 \mathrm{~N} 225^{\circ} \mathrm{C}$ sebesar 37,3 ppm pada $2500 \mathrm{rpm}$ dan peningkatan gas $\mathrm{CO}_{2}$ terbaik filter alami $0,84 \%$ pada $2500 \mathrm{rpm}, 0,98 \%$ pada $4500 \mathrm{rpm}$.
\end{abstract}

Kata kunci: Filter udara zeolit, fly ash, aktivasi $\mathrm{HCl}$, prestasi sepeda motor.

\section{Pendahuluan}

Ketergantungan masyarakat terhadap bahan bakar minyak sangatlah tinggi hal ini karena dari segi keterjangkauannya dalam harga dan cadangan dan produksi minyak Indonesia yang masih tinggi. Akibatnya bahan bakar minyak menjadi salah satu bahan bakar yg paling banyak digunakan dari pada bahan bakar lainnya.

Menurut Direktur Jendral Minyak dan Gas Bumi (MIGAS) Kementrian Energi dan Sumber Daya Mineral (ESDM) I.G.N. Wiradmaja Puja mengatakan 'JJika dibandingkan data Satuan Kerja Khusus Pelaksana Kegiatan Kerja Hulu Minyak dan Gas Bumi (SKK MIGAS) cadangan minyak tahun 2000 sebesar 5.008 mmtbs lebih besar dari pada cadangan minyak pada tahun 2016 sebesar 2.933 million stock tank barrels (mmstb)' [1]. Dan dimung- kinkan cadangan minyak Indonesia hanya bisa bertahan hingga tahun 2028, karena produksi minyak saat ini pertahunnya mencapai 288 juta barel pertahun, sedangkan jumlah cadangan minyak indonesia saat ini sebesar 3,6 miliar barel. Salah satu cara untuk memperpanjang umur cadangan minyak adalah dengan cara menghemat penggunaan bahan bakar minyak dengan cara memanfaatkan fly ash batubara dan zeolit alam sebagai penyaring udara (filter) kendaraan. 
Pemanfaatan batu alam zeolit sebagai penyaring udara pembakaran. Karena pada prinsipnya, Zeolit memiliki kemampuan dalam menangkap gas nitrogen dalam udara, hal ini didasarkan atas sifat-sifat mineralogi, fisik dan kimia yang dimiliki Zeolit [2]. Kemampuan zeolit dan fly ash dalam meningkatkan prestasi mesin telah dibuktikan oleh Eko (2017), penggunaan fly ash dan zeolit sebagai filter udara berhasil untuk menghemat bahan bakar pada pengujian stasioner sebesar 53,06 \% (7,666 $\mathrm{ml}$ dari $16,333 \mathrm{ml}$ ), pada pengujian berjalan sejauh $5 \mathrm{~km}$ dengan kecepatan konstan 60 $\mathrm{km} / \mathrm{jam}$ sebesar $33,43 \%$. Dan pada pengujjian akselerasi kecepatan 0-80 $\mathrm{km} / \mathrm{jam}$ dan kecepatan 40-80 dengan persentasi peningkatan prestasi mesin mencapai $21 \%$ dan mampu mereduksi emisi gas buang $\mathrm{CO}$ dan $\mathrm{HC}$ sebesar 17,738 $\%$ dan $26,978 \%$ pada 1500 rpm dan 38,473 $\%$ dan $30 \%$ pada $3500 \mathrm{rpm}$ [3].

Dari penelitian Ajito Surancoyo (2017), kemampuan zeolit dan fly ash yang di aktivasi $\mathrm{NaOH}-$ Fisik terbukti mampu mengurangi konsumsi bahan bakar pada pengujian berjalan sebesar $8,2 \%(7,4 \mathrm{ml})$, pada pengujian akselerasi dengan flter udara zeolit dan fly ash dapat mempercepat $14,43 \%$ (2,57 s lebih cepat), dan yang terbaik pada pengujian stasioner dengan total persentasi keseluruhan rpm pengujian sebesar 49,82\% (9,7 $\mathrm{ml}$ lebh hemat) [4].

Prestasi mesin sangat erat hubungannya dengan parameter operasi suatu kendaraan, besar kecilnya harga parameter operasi kendaraan akan menentukan tinggi rendahnya prestasi mesin yang dihasilkan. Untuk mengukur prestasi kendaraan motor bensin 4 langkah dalam aplikasinya diperlukan parameter yaitu konsumsi bahan bakar, kadar gas buang dan tenaga mesin [5].

Berdasarkan beberapa penelitian yang telah dilakukan tersebut, penulis ingin melakukan penelitian zeolit dan fly ash (batubara) dengan aktivai HCl-fisik guna untuk meningkatkan prestasi mesin pada sepeda motor bensin 4 langkah serta mengurangi emisi gas buang pada sepeda motor bensin 4 langkah.

\section{Metode Penelitian}

\section{Persiapan filter Zeolit dan Fly ash}

Tahap pertama dalam persiapan filter zeolit dan fly ash adalah mengaktivasi zeolit dan fly ash dengan zat kimia asam $\mathrm{HCl}$ dengan normalitas $0,25 \mathrm{~N} ; 0,5 \mathrm{~N} ; 0,75 \mathrm{~N}$; $1 \mathrm{~N}$; dan 1,5 N. Kemudian menyamakan ukuran zeolit dan fly ash dengan cara ditumbuk hingga halus kemudian disaring dengan ayakan dengan ukuran 100 mesh. Setelah ukuran zeolit dan fly ash sama, selanjutnya zeolit dan fly ash dicampur perekat yang terbuat dari campuran tepung dengan air aquades hingga menjadi adonan zeolit dan fly ash. Kemudian adonan zeolit dan fly ash dicetak menggunakan cetakan pellet dengan ketebalan $3 \mathrm{~mm}$ dan diameter pellet $10 \mathrm{~mm}$. Pellet didiamkan selama semalam kemudian di-oven dengan suhu $100{ }^{\circ} \mathrm{C}, 150{ }^{\circ} \mathrm{C}, 175^{\circ} \mathrm{C}, 200^{\circ} \mathrm{C}$ dan $225^{\circ} \mathrm{C}$. Langkah terakhir yaitu pellet disusun dalam filter buatan yang terbuat dari kawat strimin dengan massa 75 gram.
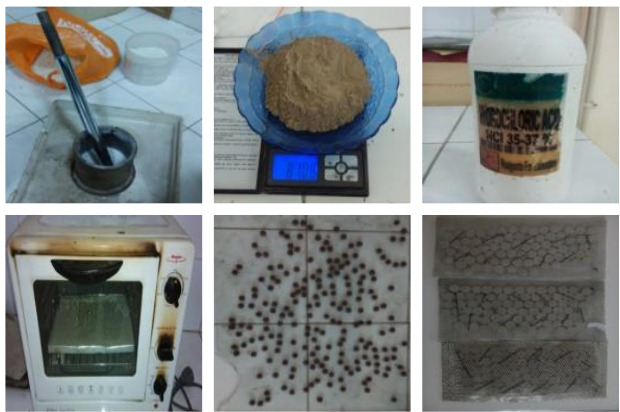

Gambar 1. Proses Aktivasi Kimia

\section{Menyiapkan Kendaraan Uji}

Pada pengujian ini peneliti menggunakan kendaraan sepeda motor produk Honda dengan tipe Supra X 125 cc pembuatan tahun 2013 memiliki kapasitas mesin sebesar $125 \mathrm{cc}$. 


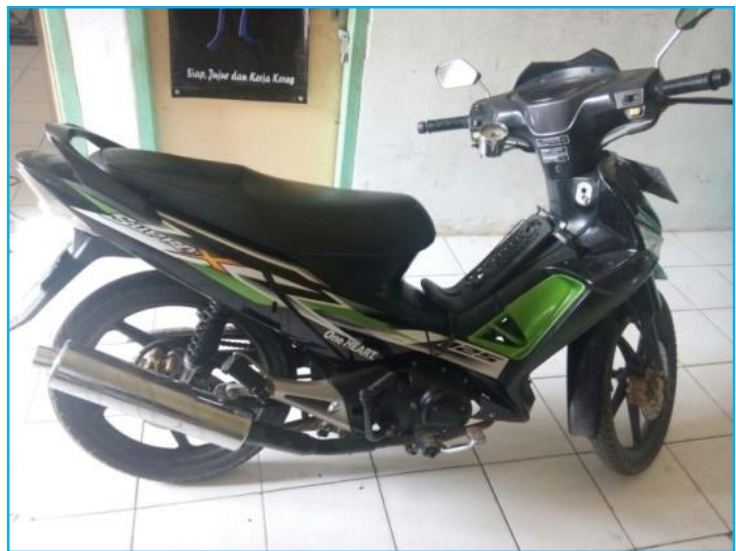

Gambar 2. Sepeda motor uji

Sebelum digunakan dalam pengujian sepeda motor uji terlebih dahulu dipasangkna tachometer untuk mengetahui putaran mesin uji yang digunakan sebagai acuan perpindahan perseneling pada saat pengujian, sehingga perlakuan perpindahan perseneling dari setiap filter sama. Kemudian tahap selanjutnya adalah dilakukanya tune-up ringan sebelum melakukan pengujian sehingga sepeda motor uji dalam keadaan baik agar pengujian mendapatkan hasil yang baik.

\section{Prosedur Pengujian}

Pengujian ini dibagi 3 tahap pengujian jalan yaitu yang pertama pengujian menentukan aktivasi kimia terbaik dengan normalitas $0,25 \mathrm{~N} ; 0,5 \mathrm{~N}$; $0,75 \mathrm{~N} ; 1 \mathrm{~N} ; 1,5 \mathrm{~N}$ dan $2 \mathrm{~N}$. Kedua yaitu pengujian menentukan temperatur pengeringan pelet terbaik dengan temperatur $150^{\circ} \mathrm{C} ; 175^{\circ} \mathrm{C} ; 200^{\circ} \mathrm{C}$ dan $225^{\circ} \mathrm{C}$. Ketiga menentukan komposisi campuran zeolit dan fly ash terbaik yaitu Z100:F0; Z75:F25; Z50:F50; Z25:F75 dan Z0:F100. Masing-masing pengujian dilakukan pengujian akselerasi 0-80 $\mathrm{km} / \mathrm{jam}$ dan dilakukan sebanyak 3 kali pengujian pada masing-masing tahap pengujian. Adapun data yang diambil dalam pengujian berjalan ini adalah waktu tempuh mesin saat akselerasi dengan berbagi tahap pengujian filter.

Tahap pertama pada proses pengujian yaitu isi bahan bakar pada tangki buatan setelah itu hidupkan mesin. Ketika gas mulai diputar, stopwacth mulai diaktifkan, setelah sampai pada kecepatan $80 \mathrm{~km} / \mathrm{jam}$ stopwacth dinon-aktifkan kemudian dicatat waktu tempuhnya. Dalam proses pengujian, pada proses perpindahan perseneling diupayakan konstan pada setiap pengujian yaitu perseneling 1 kecepatan $0-30 \mathrm{~km} / \mathrm{jam}$, perseneling 2 kecepatan $30-50 \mathrm{~km} / \mathrm{jam}$, perseneling $3 \quad 50-70 \quad \mathrm{~km} / \mathrm{jam}$ dan perseneling 4 kecepatan 70-80 km/jam. Dilakukan pada lintasan lurus dengan panjang lintasan kurang lebih $1 \mathrm{~km}$.

\section{Hasil dan Pembahasan}

Proses pertama pengujian ini adalah menentukan komposisi zeolit dan fly ash pada pellet filter buatan, Komposisi zeolit dan fly ash yang digunakan adalah Z100:F0; Z75:F25; Z50:F50; Z25:F75 dan Z0:F100.

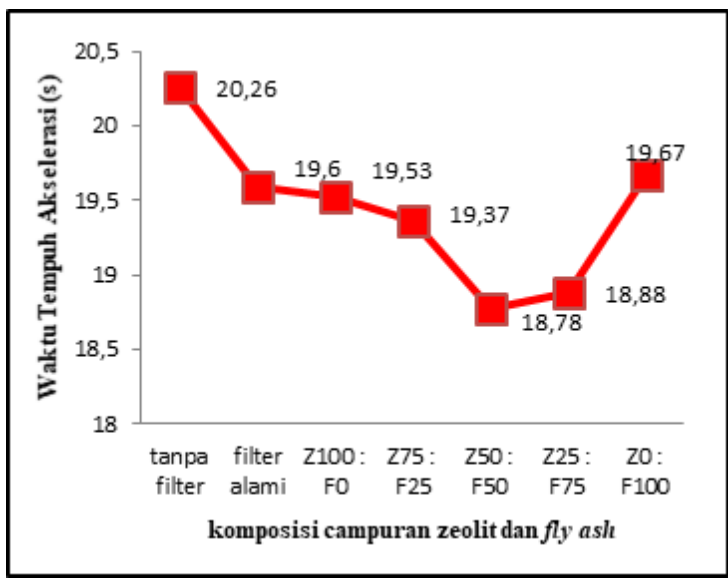

Gambar 3. Komposisi campuran zeolit dan fly ash terhadap waktu tempuh pada uji akselerasi kendaraan uji

Dapat dilihat pada gambar 3 bahwa filter dengan komposisi Z50 : F50 terbaik dalam pengujian akselerasi dengan mendapatkan waktu tercepat, waktu tempuh rata-rata $18,78 \mathrm{~s}$ lebih cepat 7,29\% dari filter tanpa zeolit dan fly ash dengan waktu tempuh rata-rata 20,26 s. Berbeda dengan filter pelet dengan komposisi zeolit $100 \%$ maupun dengan fly ash $100 \%$. Kedua filter tersebut memperoleh waktu tempuh tercepat ke-empat dengan waktu tempuh rata-rata $19,53 \mathrm{~s}$ dan ke-enam dengan waktu tempuh rata-rata 19,67 dari filter tanpa zeolit dan fly ash dengan waktu tempuh rata-rata 20,26 s. Seetelah mendapatkan komposisi zeolit dan fly ash 
terbaik selanjutnya menentukan nilai konsentrasi kimia $\mathrm{HCl}$ terbaik.

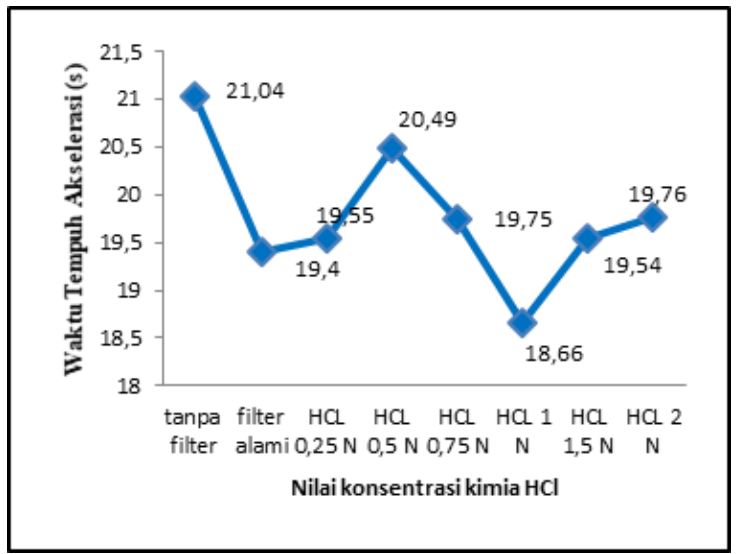

Gambar 4. Nilai konsentrasi kimia $\mathrm{HCl}$ terhadap waktu tempuh pada uji akselerasi kendaraan uji

Nilai konsentrasi $\mathrm{HCl}$ terbaik pada uji akselerasi ini adalah $1 \mathrm{~N}$ dengan waktu tempuh $18,66 \mathrm{~s}$ lebih singkat $12,56 \%$ dari filter tanpa zeolit dan fly ash selama 21,34 s. Untuk filter alami zeolit dan fly ash tanpa diberi perlakuan aktivasi kimia $\mathrm{HCl}$ menghasilkan rata-rata waktu tempuh tercepat kedua yaitu $19,40 \mathrm{~s}$ lebih singkat $9,12 \%$ dari filter tanpa zeolit dan fly ash selama 21,34 s. Setelah mendapatkan nilai konsentrasi terbaik maka pengujian yang terakhir adalah mencari aktivasi temperatur terbaik.

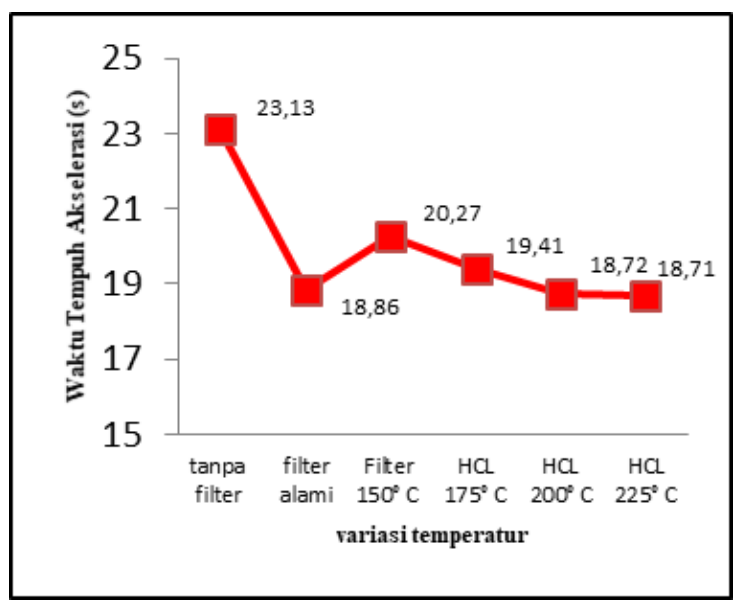

Gambar 5. Variasi aktivasi temperature terhadap waktu tempuh pada uji akselerasi kendaraan uji

Hasil pengujian terbaik pada pengujian akselerasi adalah filter pelet dengan temperatur pengeringan $225^{\circ} \mathrm{C}$ dengan waktu tempuh $18,71 \mathrm{~s}$ lebih singkat
$19,11 \%$ dari filter tanpa zeolit dan fly ash selama 23,13 s, Filter terbaik kedua pada pengujian akselerasi adalah filter pelet dengan temperatur pengeringan $200^{\circ} \mathrm{C}$ dengan waktu tempuh 18,72 s lebih singkat $19,08 \%$ dari filter tanpa zeolit dan fly ash selama $23,13 \mathrm{~s}$, pada filter pelet $150^{\circ} \mathrm{C}$ didapatkan waktu tempuh rata-rata selama 20,27 s lebih hemat $12,38 \%$ dan pada filter pelet $175^{\circ} \mathrm{C}$ didapatkan waktu tempuh ratarata selama 19,41 s lebih hemat $16,10 \%$.

\section{Kesimpulan}

Filter zeolit dan fly ash dengan normalitas kimia $\mathrm{HCl}$ terbukti dapat meningkatkan tenaga mesin pada motor bensin 4-langkah, filter terbaik dalam meningkatkan tenaga mesin adalah filter dengan normalitas $1 \mathrm{~N}$ temperatur pengeringan $225^{\circ} \mathrm{C}$ komposisi $\mathrm{Z} 75: \mathrm{F} 25$ meningkatkan tenaga mesin sebesar 19,11 $\%$ (4,42 s lebih cepat), terbaik kedua adalah filter dengan normalitas $1 \mathrm{~N}$ temperatur pengeringan $200^{\circ} \mathrm{C}$ komposisi Z75:F25 meningkatkan tenaga mesin sebesar 19,08 $\%(4,41 \mathrm{~s}$ lebih cepat) dari pada filter tanpa menggunakan zeolit dan fly ash normalitas $\mathrm{HCl}$ sebesar 23,13s.

Semakin tinggi temperatur aktivasi yang diberikan (tanpa melebihi batas suhu aktivasi maksimum zeolit dan Fly ash), maka semakin baik juga kemampuan zeolit dan Fly ash sebagai adsorben. Hal ini dibuktikan pada saat menentukan temperatur aktivasi terbaik yang didapat pada variasi temperatur yang paling tinggi yaitu $225^{\circ} \mathrm{C}$ dengan persentase terbaik pada uji akselerasi sebesar 15,23\%.

\section{Referensi}

[1]. Amelia, Anggita Rezki. 2016. Cadangan Minyak Habis 12 Tahun Lagi, Pemerintah Fokus Energi Baru. Badan Pengatur Hilir Minyak dan Gas Bumi. www.bphmigas.go.id. Diakses pada 04 Oktober 2017. 
[2]. Nirwata, Sonic. 2011. Aplikasi Zeolit Pellet Perekat yang Diaktivasi Basa-fisik untuk Mengamati Prestasi Mesin Sepeda Motor Bensin 4Langkah. Skripsi Program Sarjana Teknik Mesin, Fakultas Teknik Universitas Lampung. Bandar Lampung.

[3]. Aprilando, Eko. 2017. Penggunaan Fly ash dan Zeolit Untuk Menghemat Bahan Bakar dan Mereduksi Emisi Gas Buang Sepeda Motor Bensin 4 Langkah. Skripsi Program Sarjana Teknik Mesin. Fakultas Teknik Universitas Lampung. Bandar Lampung.

[4]. Surancoyo, Ajito. 2017. Pengaruh Filter Udara Berbahan Zeolit dan Fly ash Batubara Aktivasi NaOH-Fisik Terhadap Prestasi Mesin Sepeda Motor 4 Langkah. Skripsi Program Sarjana Jurusan Teknik Mesin, Fakultas Teknik Mesin Universitas Lampung. Bandar Lampung.

[5]. Yudi dan Wardono. 2017. Modul Praktikum Pengujian Prestasi Mesin Motor Bakar Diesel 4-Langkah.Bandar Lampung. Jurusan Teknik Mesin Fakultas Teknik Universitas Lampung. 